\title{
IS THERE ANY INFLUENCE OF PERSONALITY DISORDER ON THE SHORT TERM INTENSIVE GROUP COGNITIVE BEHAVIORAL THERAPY OF SOCIAL PHOBIA?
}

\author{
Jana Vyskocilova ${ }^{\mathrm{a}}$, Jan Prasko ${ }^{\mathrm{a}, \mathrm{b}, \mathrm{c}, \mathrm{d} *}$, Tomas Novak ${ }^{\mathrm{a}, \mathrm{d}}$, Libuse Pohlova ${ }^{\mathrm{a}}$ \\ a Prague Psychiatric Centre, Ustavni 91, 18103 Praha, Czech Republic \\ ${ }^{b}$ Department of Psychiatry, University Hospital Olomouc \\ c Psychiatry Clinic, Faculty of Medicine and Dentistry, Palacky University Olomouc \\ d Centre of Neuropsychiatric Studies, Ustavni 91, 18103 Praha \\ E-mail:prasko@fnol.cz
}

Received: April 24, 2010; Accepted: July 21, 2010

Key words: Social phobia/Personality disorders/Controlled study/Cognitive-behavioral therapy/Antidepressants

Backround. The treatment of personality disorder is repeatedly reported as less successful than the treatment of patients without personality disorder. Most clinicians believe that anxiety disorder in tandem with a personality disorder often leads to longer treatment, worsens the prognosis, and thus increases treatment costs. Our study was designed to compare the short-term effectiveness of therapy in patients suffering from social phobia with and without personality disorder.

Method. The specific aim of the study was to assess the efficacy of a 6 week therapeutic program designed for social phobia (SSRIs and CBT) in patients suffering from social phobia with comorbid personality disorder (17 patients) and social phobia without comorbid personality disorder (18 patients). The patients were regularly assessed in weeks 0, 2, 4 and 6 using the CGI (Clinical Global Improvement) for severity, LSAS (Liebowitz Social Anxiety Scale), and in self-assessments BAI (Beck Anxiety Inventory) and BDI (Beck Depression Inventory).

Results. Patients in both groups improved their scores in most of the assessment instruments used. A combination of CBT and pharmacotherapy proved to be the most effective treatment for patients suffering with social phobia with or without comorbid personality disorder. Treatment efficacy in patients with social phobia without personality disorder was significantly better than in the group with social phobia comorbid with personality disorder for CGI and specific inventory for social phobia - LSAS. The scores on the subjective depression inventory (BDI) also showed significantly greater decrease over the treatment in the group without personality disorder. The treatment effect between groups did not differ in subjective general anxiety scales BAI.

Conclusion. Our study showed that patients suffering from social phobia and comorbid personality disorder showed a smaller decrease in specific social phobia symptomatology during treatment compared than patients with social phobia without personality disorders. However, a significant decrease in symptomatology occurred in personality disorder patients as well.

\section{INTRODUCTION}

Social phobia is characterized by marked and persistent fear of embarrassment or humiliation in situations involving performance or interaction with or scrutiny by others. Social phobia is a relatively common disorder causing impaired social and occupational adaptation. The lifetime prevalence of social phobia is $13.3 \%\left(\operatorname{ref}^{1}\right)$. It is a chronic disorder which often begins in puberty and adolescence, has a continuous course and leads to serious consequences ${ }^{2}$. It has a low rate of natural remission, producing substantial decrease in the quality of life and a large number of social role impairments and disabilities. Social phobia occurs in males and females in the same frequency. There is no influence of intelligence, education, economic background or employment on its occurrence $^{3}$. People with social phobia tend to be financially dependent, often need specialized care, have more suicidal thoughts and suicide attempts, show increased risk of secondary psychiatric comorbidity, especially alcohol abuse and addiction, depression, are rarely married and have major difficulties with work adaptation ${ }^{4}$. Population and clinical studies also show that these patients are seldom treated adequately ${ }^{5-8}$.

Over the past 15 years, behavioral, cognitive, and cognitive behavioral procedures (primarily exposure and cognitive reconstruction based treatments) have been found effective in the treatment of social phobia. Cognitive behavioral therapy (CBT) is typically a timelimited psychosocial intervention, administered either in individual or group settings, that has demonstrated clear efficacy for the treatment of SAD ${ }^{9,10}$. Typical components of CBT include psychoeducation, somatic management techniques such as muscle relaxation, in vivo and imaginal exposure, video feedback, cognitive restructuring, and social skills training ${ }^{9,11}$. CBT has demonstrated efficacy comparable to that of pharmacotherapy, with a slightly slower onset of therapeutic effect but greater persistence 
of benefit after treatment discontinuation ${ }^{12-16}$. Members in group CBT program have the opportunity to try out and practice basic social skills which they can use later in their natural environment ${ }^{17}$. From the long term point of view it can be more effective than pharmacotherapy (SSRI use) only. In comparison with the general population, however, one study showed that while two thirds of patients significantly improve only about half reached normal levels of anxiety in social situations after treatment ${ }^{3}$. Although combined pharmacotherapy and CBT may be presumed to be more effective than either intervention administered individually, evidence from one large RCT with fluoxetine and CBT did not demonstrate a significant advantage for the combined intervention over each effective monotherapy ${ }^{18}$. In a study from our department Prasko et al. ${ }^{17}$ compared the effectiveness of a 6 month and 2 year follow up of three outpatient treatment programs (moclobemide with clinical management, cognitive - behavioral therapy with placebo, and the combination of moclobemide with cognitive behavioral therapy) in patients with social phobia. All three therapeutic approaches proved highly effective. Moclobemide alone was the most immediate in reducing general anxiety and social anxiety in the first two months of treatment but its influence on behavior was less expressed. The combination of pharmacotherapy and CBT was the most effective in the 6-month assessments in all measures. CBT with placebo was most effective in reducing avoidant behavior but the reduction in anxiety itself manifest later than for moclobemide. In a two-year follow up, the best on all rating scales were groups initially treated with CBT with placebo or CBT with moclobemid.

Personality disorders are relatively frequent in the general population with a prevalence ranging from $10 \%$ to $13 \%\left(\mathrm{ref}^{19}\right)$. Among the outpatient psychiatric population, 30-50\% suffers from personality disorders ${ }^{20}$ and about $15 \%$ of inpatients come to health care facilities because of problems related primarily to their personality disorders. Up to half of the remaining inpatients suffers from comorbid personality disorder ${ }^{21}$. Social phobia can be associated with any personality disorder, particularly with an avoidant one. People with social phobia, however, often suffer from other personality disorders, such as borderline, narcissistic, dependent and paranoid disorders ${ }^{17}$. A diagnosis of personality disorder often evokes images of troublesomeness, difficult work with little hope for success and this correspondingly affects the therapist's conscious or unconscious attitudes from the very beginning of his relationship with the patient. These attitudes are often negative, moralising and, according to Tyrer and Davidson ${ }^{22}$, sometimes rigid or even "delusional". Personality disorders rarely occur separately and are often related to other health problems, such as depressive states, anxiety disorders, eating disorders, alcohol and drug abuse, promiscuity, injury, infectious diseases etc. Most clinicians believe that the occurrence of these problems in tandem with a personality disorder often leads to longer treatment, worsens the prognosis, and thus increases treatment costs. However, the latest overview of empirical psychotherapeutic studies of personality disorders shows that, despite the myth of untreatability, treatment is relatively effective ${ }^{23}$. The authors carried out a meta-analysis of 22 studies showing that significant positive changes during active treatment are 2-4 times higher than in control groups without any active treatment. In four studies with treatment outcome criterion of full remission, $52 \%$ of patients met this criterion after 1.3 years of treatment. Although the improvement is not as fast and substantial as for anxiety disorders or depression, there is still a significant reduction in the patients' suffering and improvement in their adaptation in life. This metaanalysis, however, is not clinically relevant to the answer the question: Does comorbid disorder influence the treatment efficacy for any particular disorder? In our study ${ }^{24}$ we found that there is smaller decline in specific panic and agoraphobic symptoms during treatment in patients with comorbid personality disorder than in patients without personality disorder. Nonetheless, there was also a significant reduction in anxiety and avoidance symptoms in patients with panic disorder/agoraphobia comorbid with personality disorders. A high percentage of these patients achieved significant overall improvement. However there is a dearth of information on co-morbidity of personality disorders in the treatment of social phobia. According to clinical perception, social phobia with comorbid personality disorder is more difficult to treat than social phobia without comorbid personality disorders ${ }^{25}$.

Approximately half of all patients admitted for social phobia to the day-care clinic of Prague Psychiatric Centre also suffer from comorbid personality disorder. Prevailing personality disorders include avoidant, borderline, narcissistic and dependent. The therapeutic programme for social phobia patients with or without personality disorders is practically the same; it lasts six weeks, unless a patient decides to quit the therapy earlier. The aim of our study was to compare the efficacy of treatment in patients with social phobia suffering from a comorbid personality disorder with the treatment of patients with social phobia with no comorbid personality disorder.

\section{METHOD}

The sample includes outpatients coming for intensive group psychotherapeutic treatment to Prague Psychiatric Center for a generalized form of social phobia. The diagnosis was confirmed by two experienced psychiatrists.

\section{Patients}

To date, 35 patients who met the following admission criteria have been included into the study (18 with social phobia without comorbid personality disorders and 17 with social phobia with comorbid personality disorder):

(a) Research criteria ICD-10 ${ }^{26}$ for Social phobia (as diagnosed by a structured interview $\mathrm{MINI}^{27}$ );

(b) Age 18-60 years;

(c) Signed informed consent to the study. 
The exclusion criteria were the following:

(a) The presence of moderate or severe depressive episodes (ICD-10 criteria for depressive episode);

(b) Organic mental disorder;

(c) History of psychotic disorder;

(d) Drug dependency;

(e) Serious somatic illness;

(f) Pregnancy and lactation in women

(g) Suicidality.

The inclusion and exclusion criteria of the study were confirmed by two independent experts. The study was approved by a joint ethical committee of the Prague Psychiatric Centre and the Psychiatric Hospital in Bohnice.

\section{Assessment}

After study enrolment, patients were assessed during the first two days of attendance at the day-care clinic before the beginning of treatment. The assessment focused on psychopathology and was carried out using psychiatric rating scales in the second, fourth and sixth week by two trained psychiatrists or with self-rating scales (Table 1).

(a) Objective rating scales - to assess the degree of psychopathology, we used following psychiatric rating scales:

- $C G I$ (Clinical Global Impression) (ref. ${ }^{28}$ ) - global assessment of the degree of psychopathology. The source of the data is an as complete as possible collection of information about the patient's behaviour.

- LSAS (Liebowitz Social Anxiety Scale) (ref. ${ }^{29}$ ) - the most commonly used scale to measure symptoms of social phobia. The patient scores in the 24 items representing typical feared social situation in two subscales (social anxiety and avoidant behavior) from 0 (no anxiety or avoidant behavior) to 3 (maximum distress or full avoidant behavior).

Self assessment rating scales:

- $B A I$ - (Beck Anxiety Inventory) (ref. ${ }^{30}$ ) - self-rating scale with 21 anxiety indicators;

- $B D I$ - (Beck Depression Inventory)(ref. ${ }^{31}$ ) - self-rating scale with 21 depression indicators.

\section{Therapeutic approaches}

All patients were treated in group cognitive-behavioral program for patients with various anxiety disorders. The CBT group program includes 18 groups of CBT (vicious circle of anxiety, cognitive restructuring, communication training, role playing, exposure therapy, relaxation, cognitive schemas accommodation, and problem solving) and 12 biographical groups which address the mapping and elaborating of cognitive schemas. Each session lasted 1.5 hour and homework is an integral part of the program. The brief CBT program is focused on the treatment of anxiety disorders and is not targeted for the treatment of personality disorders. The concrete steps of the program are described in detail in the manual ${ }^{32}$. Pharmacotherapy with SSRI antidepressants was administered if patients wished. If a patient came to the treatment without drugs or disagreed with the using of medication, he/she was treated with CBT only (13 patients). Medicated patients were taking SSRI in the normal range and during the CBT program this remained unchanged. A few patients were receiving low doses of second generation antipsychotics and we did not change it. Eight patients were also using small doses of anxiolytics (alprazolam, average dose $1.15 \mathrm{mg}$ per day, range $0.75-1.5)$. We gradually decreased doses in all patients to be free of anxiolytics at the end of the treatment.

\section{Statistical methods}

Descriptive statistics were applied to all demographic variables. Only patients, who completed the 6-month treatment, were included in the analysis. The data are presented as means and SD. Patient demographic and baseline clinical characteristics were compared between treatment groups and analyzed using the two-sample t-test or the Mann-Whitney U test and chi-square test or Fisher's exact test for continuous and categorical variables, respectively. The data for the LSAS, CGI and BAI passed the normality testing (Kolmgorov-Smirnov). Analysis of variance (ANOVA) was used to evaluate the change in psychometric measures during the study. The interaction between group and time was evaluated by a two-way ANOVA. The chi ${ }^{2}$-test was used in analyzing the change in the CGI score. For all statistical tests a 5\% significance level was chosen. Statistical computing was performed with Statsoft Statistica version 7.0 software).

\section{RESULTS}

Thirty five patients were eventually included into the study (16 men and 19 women). Seventeen patients fulfilled ICD-10 research criteria for comorbid personality disorder (for patients characteristics see Table 2). There were no statistically significant differences among the patients suffering from social phobia with comorbid per-

Table 1. Time table

- assessment and measurement methods.

\begin{tabular}{|l|c|c|c|c|}
\hline Method & Week 0 & Week 2 & Week 4 & Week 6 \\
\hline $\begin{array}{l}\text { ICD -10 diagnostic } \\
\text { criteria }\end{array}$ & $\mathrm{X}$ & & & \\
\hline MINI & $\mathrm{X}$ & & & \\
\hline CGI-severity & $\mathrm{X}$ & $\mathrm{X}$ & $\mathrm{X}$ & $\mathrm{X}$ \\
\hline BAI & $\mathrm{X}$ & $\mathrm{X}$ & $\mathrm{X}$ & $\mathrm{X}$ \\
\hline BDI & $\mathrm{X}$ & $\mathrm{X}$ & $\mathrm{X}$ & $\mathrm{X}$ \\
\hline LSAS & $\mathrm{X}$ & $\mathrm{X}$ & $\mathrm{X}$ & $\mathrm{X}$ \\
\hline
\end{tabular}

ICD - 10: international classification of the disorders 10. revision; MINI: Mini international neuropsychiatric interview; CGI: Clinical global impression; BAI: Beck anxiety inventory; BDI: Beck depressive inventory; LSAS: Liebowitz social anxiety scale 
sonality disorder and patients with social phobia without comorbid personality disorders either in terms of demographic characteristics such as age, sex, marital status and employment (see Table 2), or in mean scores of rating scales CGI, LSAS and BAI (unpaired t-test: ns; see Table 3 ) at the beginning. Nevertheless the group with personality disorders had a statistically significant lower level of education than the group without personality disorders $\left(\mathrm{chi}^{2}: \mathrm{p}<0.005\right)$, and a statistically significant higher frequency of comorbid current disorders $\left(\mathrm{chi}^{2}: \mathrm{p}<0.05\right)$ (see Table 2). There was also a significant difference between groups in the subjective evaluation of depressive symptoms - the group with comorbid personality disorders subjectively experienced higher rates of depression (as assessed by BDI, unpaired t-test: $\mathrm{p}<0.005$, see Table 3 ).

The borderline (29\%) and avoidant (29\%) personality disorder were the most common personality disorder comorbid with social phobia in our study. Comorbidity of other psychiatric disorders in both groups was relatively large: thirteen patients (i.e. 76\%) of group with social phobia and personality disorders and eight patients (i.e. 44\%) of group with social phobia without personality disorder suffered from other current psychiatric disorder (Table 2). There was higher percentage of other comorbid psychiatric disorders in the group with personality disorder than in the group without personality disorders (difference between groups was statistically significant: chi $^{2}: \mathrm{p}<0.05$ ). Our hypothesis, that social phobia patients with personality disorder suffer significantly more often from current comorbidity disorders than the social phobias patients without personality disorder, was confirmed.

\section{Treatment}

Patients were treated with group CBT and pharmacotherapy or with group CBT only (13 patients). The CBT programme was standardized. Twelve patients used

Table 2. Characteristics of the patients admitted to the study.

\begin{tabular}{|c|c|c|c|}
\hline & $\begin{array}{c}\text { Social phobia } \\
\text { with personality } \\
\text { disorder }\end{array}$ & $\begin{array}{c}\text { Social phobia } \\
\text { without personality } \\
\text { disorder }\end{array}$ & $\begin{array}{c}\text { Chi }^{2} \text { or Fischer's } \\
\text { test }\end{array}$ \\
\hline Age & $29.06 \pm 2.625$ & $32.17 \pm 2.401$ & n.s. \\
\hline Gender: male : female & $7: 10$ & $9: 9$ & n.s. \\
\hline $\begin{array}{l}\text { Marital status (Single: Married: } \\
\text { Divorced/Widowed) }\end{array}$ & 14: $2: 1$ & 12: $4: 2$ & n.s. \\
\hline $\begin{array}{l}\text { Education basal: secondary school: } \\
\text { university }\end{array}$ & $4: 13: 0$ & $2: 10: 6$ & $\mathrm{p}<0.005$ \\
\hline Employment: yes: no & $10: 7$ & $13: 5$ & n.s. \\
\hline $\begin{array}{l}\text { Personality Disorder } \\
\text { Histrionic } \\
\text { Narcissistic } \\
\text { Avoidant } \\
\text { Dependent } \\
\text { Borderline } \\
\text { Schizoid } \\
\text { Anancastic } \\
\text { Paranoid }\end{array}$ & $\begin{array}{l}17 \\
2 \\
3 \\
5 \\
1 \\
5 \\
3 \\
1 \\
1\end{array}$ & 0 & \\
\hline Comorbidity - current disorder & $13(76 \%)$ & $8(44 \%)$ & $\mathrm{p}<0.05$ \\
\hline $\begin{array}{l}\text { Dysthymia } \\
\text { Panic disorder /agoraphobia } \\
\text { GAD } \\
\text { Depressive disorder } \\
\text { Obsessive compulsive disorder } \\
\text { Adaptation disorder } \\
\text { Alcohol misuse } \\
\text { Somatoform disorder } \\
\text { Gambling } \\
\text { Balbuties }\end{array}$ & $\begin{array}{l}1(6 \%) \\
2(11 \%) \\
2(11 \%) \\
2(11 \%) \\
1(6 \%) \\
1(6 \%) \\
2(11 \%) \\
2(11 \%) \\
0 \\
0\end{array}$ & $\begin{array}{c}0 \\
3(16 \%) \\
2(11 \%) \\
0 \\
1(5 \%) \\
\\
0 \\
0 \\
0 \\
1(5 \%) \\
1(5 \%)\end{array}$ & \\
\hline With medication: without medication & $12: 5$ & $10: 8$ & n.s. \\
\hline
\end{tabular}


Table 3. Changes in rating scales.

\begin{tabular}{|c|c|c|c|c|c|c|}
\hline \multirow[b]{2}{*}{ Rating scale } & \multirow[b]{2}{*}{ Time } & \multicolumn{2}{|c|}{$\begin{array}{l}\text { Social phobia with } \\
\text { personality disorder } \\
\qquad(\mathrm{n}=17)\end{array}$} & \multicolumn{2}{|c|}{$\begin{array}{c}\text { Social phobia } \\
\text { without personality } \\
\text { disorder } \\
(\mathrm{n}=18)\end{array}$} & \multirow{2}{*}{$\begin{array}{c}\text { Statistics: } \\
\text { unpair t-tests } \\
\text { p value }\end{array}$} \\
\hline & & Mean & SD & Mean & SD & \\
\hline \multirow[t]{4}{*}{ CGI } & Week 0 & 5.06 & 0.56 & 4.72 & 0.67 & ns \\
\hline & Week 2 & 4.71 & 0.77 & 4.17 & 0.62 & $\mathrm{p}<0.05$ \\
\hline & Week 4 & 4.00 & 0.79 & 3.22 & 0.55 & $\mathrm{p}<0.005$ \\
\hline & Week 6 & 3.47 & 0.87 & 2.33 & 0.59 & $\mathrm{p}<0.0001$ \\
\hline One-way ANOVA for repeated measures & $\mathrm{p}$ value & $\mathrm{p}<0.0001$ & & $\mathrm{p}<0.0001$ & & \\
\hline Two-way ANOVA, interaction group $x$ time & $\mathrm{p}$ value & \multicolumn{4}{|c|}{ n.s. } & \\
\hline \multirow[t]{4}{*}{ BAI } & Week 0 & 20.24 & 10.41 & 18.94 & 8.38 & ns \\
\hline & Week 2 & 24.41 & 8.80 & 22.56 & 10.63 & ns \\
\hline & Week 4 & 21.76 & 9.81 & 16.89 & 9.46 & ns \\
\hline & Week 6 & 18.76 & 10.02 & 14.33 & 6.77 & ns \\
\hline One-way ANOVA for repeated measures & $\mathrm{p}$ value & ns & & $\mathrm{p}<0.005$ & & \\
\hline Two-way ANOVA, interaction group $x$ time & $\mathrm{p}$ value & \multicolumn{4}{|c|}{ ns } & \\
\hline \multirow[t]{4}{*}{ BDI } & Week 0 & 23.65 & 8.45 & 14.72 & 6.45 & $\mathrm{p}<0.005$ \\
\hline & Week 2 & 22.47 & 9.25 & 14.33 & 9.98 & $\mathrm{p}<0.05$ \\
\hline & Week 4 & 20.59 & 10.69 & 11.00 & 6.07 & $\mathrm{p}<0.005$ \\
\hline & Week 6 & 18.47 & 9.17 & 8.50 & 6.00 & $\mathrm{p}<0.001$ \\
\hline One-way ANOVA for repeated measures & $\mathrm{p}$ value & $\mathrm{p}<0.005$ & & $\mathrm{p}<0.001$ & & \\
\hline Two-way ANOVA, interaction group $x$ time & $\mathrm{p}$ value & \multicolumn{4}{|c|}{ ns } & \\
\hline \multirow[t]{4}{*}{ LSAS-anxiety } & Week 0 & 41.12 & 10.78 & 37.61 & 12.87 & ns \\
\hline & Week 2 & 35.94 & 12.41 & 33.39 & 12.30 & ns \\
\hline & Week 4 & 32.00 & 11.39 & 27.67 & 11.29 & ns \\
\hline & Week 6 & 32.41 & 11.55 & 21.78 & 10.28 & $\mathrm{p}<0.01$ \\
\hline One-way ANOVA for repeated measures & $\mathrm{p}$ value & $\mathrm{p}<0.001$ & & $\mathrm{p}<0.001$ & & \\
\hline Two-way ANOVA, interaction group $x$ time & $\mathrm{p}$ value & \multicolumn{4}{|c|}{ ns. } & \\
\hline \multirow[t]{4}{*}{ LSAS-avoidance } & Week 0 & 34.53 & 14.72 & 35.39 & 13.51 & ns \\
\hline & Week 2 & 32.12 & 14.11 & 29.00 & 13.69 & ns \\
\hline & Week 4 & 29.59 & 14.64 & 23.72 & 12.97 & ns \\
\hline & Week 6 & 25.65 & 15.94 & 18.61 & 9.80 & ns \\
\hline One-way ANOVA for repeated measures & $\mathrm{p}$ value & $\mathrm{p}<0.005$ & & $\mathrm{p}<0.001$ & & \\
\hline Two-way ANOVA, interaction group $x$ time & $\mathrm{p}$ value & \multicolumn{4}{|c|}{ ns. } & \\
\hline \multirow[t]{4}{*}{ LSAS-total } & Week 0 & 75.65 & 24.74 & 73.61 & 25.76 & ns \\
\hline & Week 2 & 69.24 & 26.32 & 62.94 & 25.30 & ns \\
\hline & Week 4 & 62.76 & 25.57 & 51.94 & 23.88 & ns \\
\hline & Week 6 & 58.71 & 26.72 & 40.61 & 19.12 & $\mathrm{p}<0.05$ \\
\hline One-way ANOVA for repeated measures & $\mathrm{p}$ value & $\mathrm{p}<0.005$ & & $\mathrm{p}<0.0001$ & & \\
\hline Two-way ANOVA, interaction group $x$ time & $\mathrm{p}$ value & \multicolumn{4}{|c|}{ ns. } & \\
\hline
\end{tabular}

medication (i.e. $71 \%$ ) of the group with personality disorders and ten patients (i.e. 56\%) of the group without personality disorders. There was no significant difference in medication use between the groups.

\section{- CGI-severity}

In the beginning, there were no significant differences in the severity scores of clinical global impression scale $(5.06 \pm 0.56$ for the patients with personality disorders versus $4.72 \pm 0.67$ for the patients without personality disorder, unpaired t-test: n.s.). The severity scores decreased significantly in both groups during treatment (week 6:
$3.47 \pm 0.87$, one-way ANOVA for repeated measures: $\mathrm{F}=$ $36.09 ; \mathrm{p}<0.0001$ for the group with personality disorders, versus $2.33+0.59$, one-way ANOVA for repeated measures: $F=91.63 ; p<0.0001$ for the group without personality disorders). There was statistically significant higher change in mean score in the group of patients without personality disorders (week 0-6: change in mean CGI score of the patients with personality disorders was 1.59 \pm 0.19 , change in mean CGI score of the patient without personality disorder was $2.39 \pm 0.16$, unpaired t-test: $\mathrm{t}=3.171 ; \mathrm{p}<0.005)$. Nevertheless there was no statistically significant interaction between groups and time in the 




Fig. 1. Clinical Global Impression.

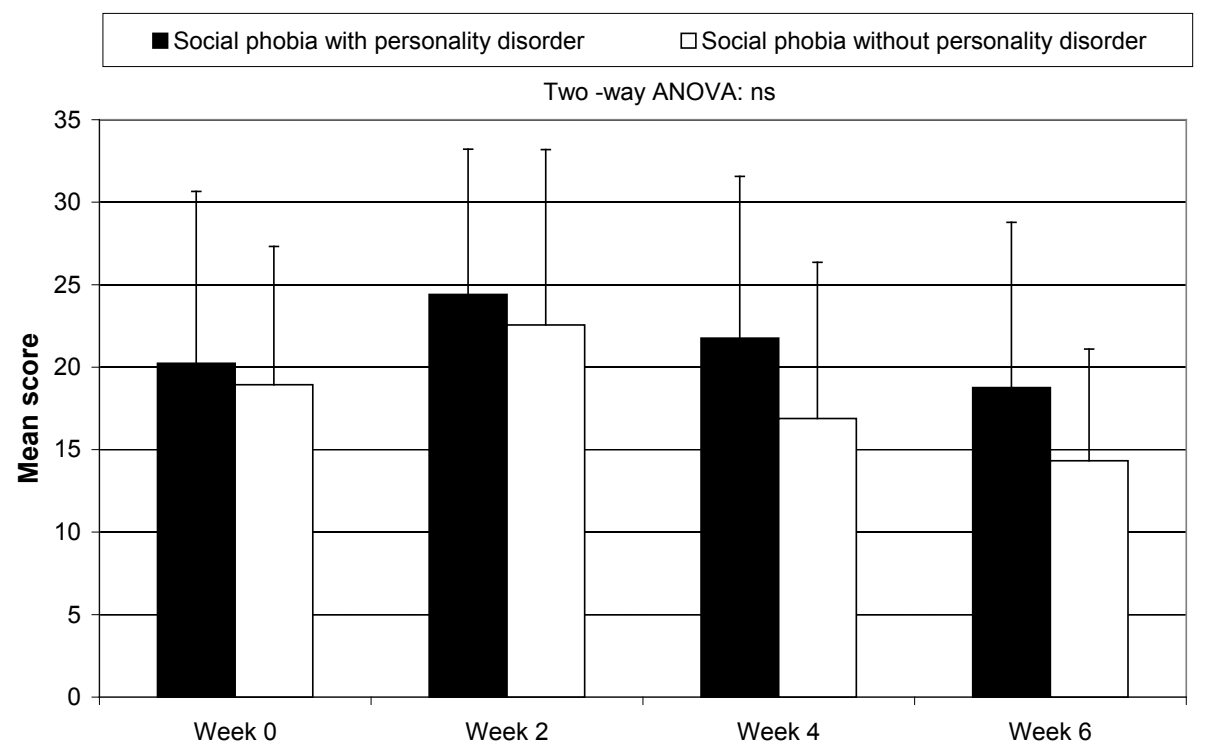

Fig. 2. Beck Anxiety Inventory.

two-way ANOVA for repeated measures $(\mathrm{F}=2.206$; $\mathrm{p}=$ 0.09) (Fig. 1).

Clinical remission was assumed when a patient achieved CGI-severity rating 1 (without symptoms) or 2 (minimal symptoms). There were only $2 / 17$ patients of the group with personality disorders achieved these figures after 6 weeks of therapy (11\%) while $13 / 18$ patients from the group without personality disorder $(72 \%)$. This difference was statistically significant (Fisher exact test: $\mathrm{p}<0.0005$ ).

\section{- BAI}

There were surprising results for the BAI scores. The baseline scores were comparable $(20.24 \pm 10.41$ in the group with personality disorders versus $18.94 \pm 8.38$ in the group without personality disorders; unpaired t-test: ns). In the first two weeks there was a slight non significant increase in general anxiety symptoms in both groups $(24.41 \pm 8.80$ in the group with personality disorders and $22.56 \pm 10.63$ in the group without personality disorders; unpaired t-test: ns). Mean scores were reduced in both groups during the course of treatment (at week 6: 18.76 $+14.33+2.431$ vs. 1.597 , unpaired t-test: ns.) (Fig. 2). The initial increase was probably related to the start of exposure therapy. The patients typically avoided social situations before the therapy and after the start of the treatment they were gradually exposed to social situations. The course of symptom reduction was very similar in both groups (one-way ANOVA for repeated measures: $\mathrm{F}=3.222 ; \mathrm{p}<0.05$ ) in the group with personality disorders and $F=5.772 ; p<0.005$ in group without personality disorders (Table 3 ) but there was no statistically significant interaction between groups and time in two-way ANOVA 


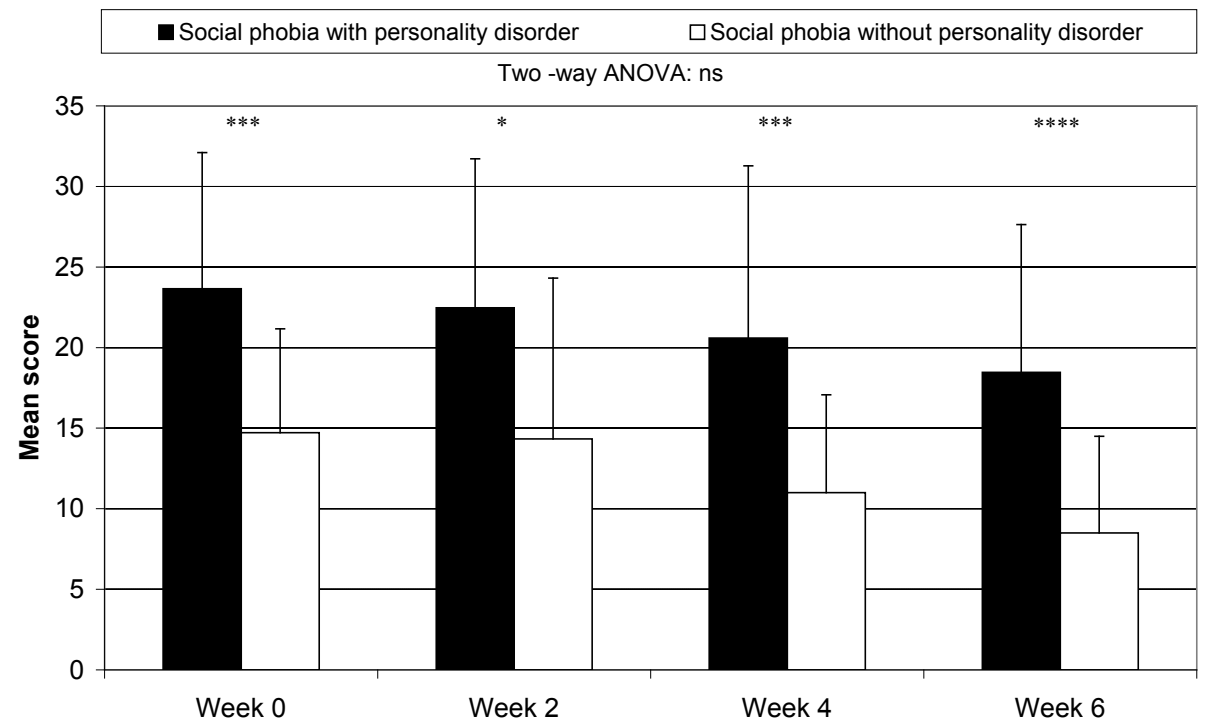

$* \mathrm{p}<0.05 ; \quad * * * \mathrm{p}<0.005 * * * * \mathrm{p}<0.001$

Fig. 3. Beck Depression Inventory.

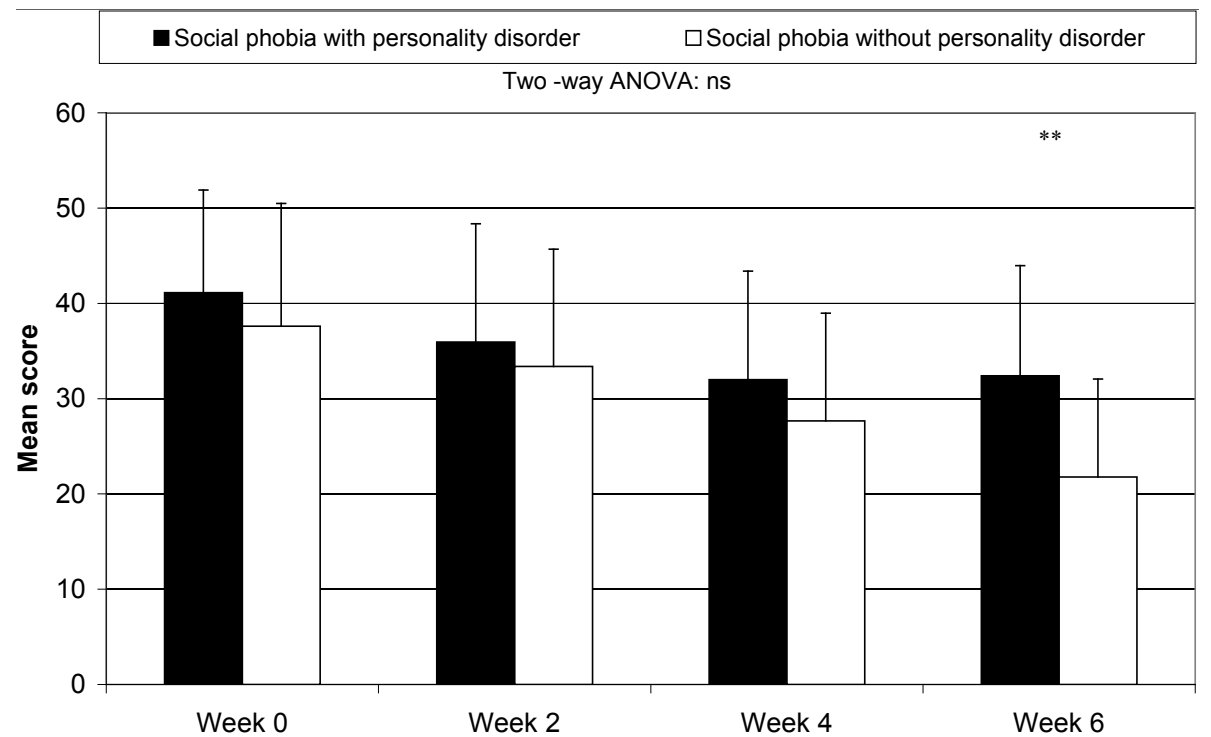

$* * \mathrm{p}<0.01$

Fig. 4. Liebowitz Social Anxiety Scale - Anxiety Subscale.

for repeated measures $(F=0.325 ; p=0.807)$. The pattern of symptom increase and decrease was very similar for both groups. No significant difference was found in either of the study visit. Subjective evaluation of a wide range of anxiety symptoms in the BDI rating scale confirmed these data. Social phobia patients - with or without personality disorder - improved rapidly during short-term treatment programme. If we ignore the specific symptoms for which they were admitted and treated, the changes are similar.

\section{- BDI}

The Beck Depression Inventory is designed for evaluating subjective depression symptoms. There was a statis- tically significant difference between groups in baseline depression scores $(23.65 \pm 8.45$ for patients with personality disorders versus $14.72+6.45$ in the second group, unpaired t-test: $\mathrm{p}<0.005)$. The mean score for the group with personality disorders was consonant with mild depression. There were similar changes in depression ratings during the treatment for both groups (mean score at week 6 in the group with personality disorder was $18.47+9.17$, one-way ANOVA for repeated measures $\mathrm{F}=4.31$; $\mathrm{p}<0.005$; and in the group without personality disorder was $8.5 \pm$ 6.00; one -way ANOVA for repeated measures: $F=5.289$; $\mathrm{p}<0.001)$. There was no statistically significant interaction between groups and time in the two-way ANOVA for repeated measures $(\mathrm{F}=0.080 ; \mathrm{p}=0.971)$ (Fig. 3). 


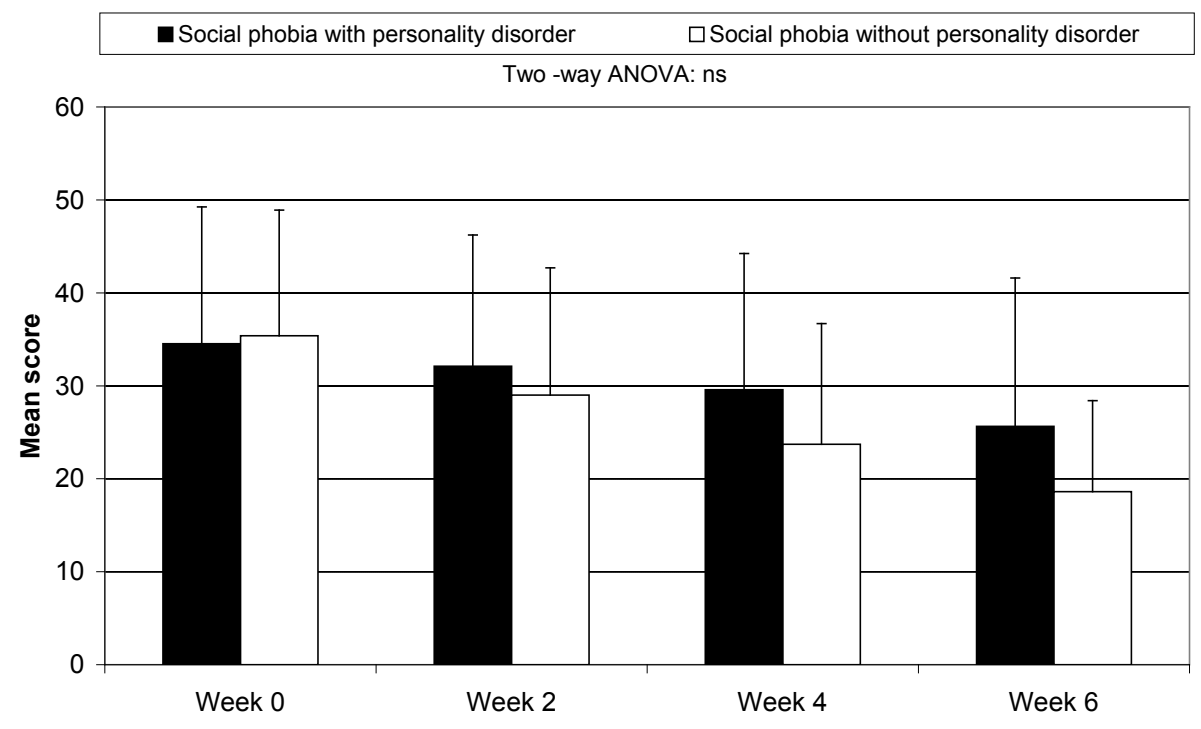

Fig. 5. Liebowitz Social Anxiety Scale - Avoidant Behavior.

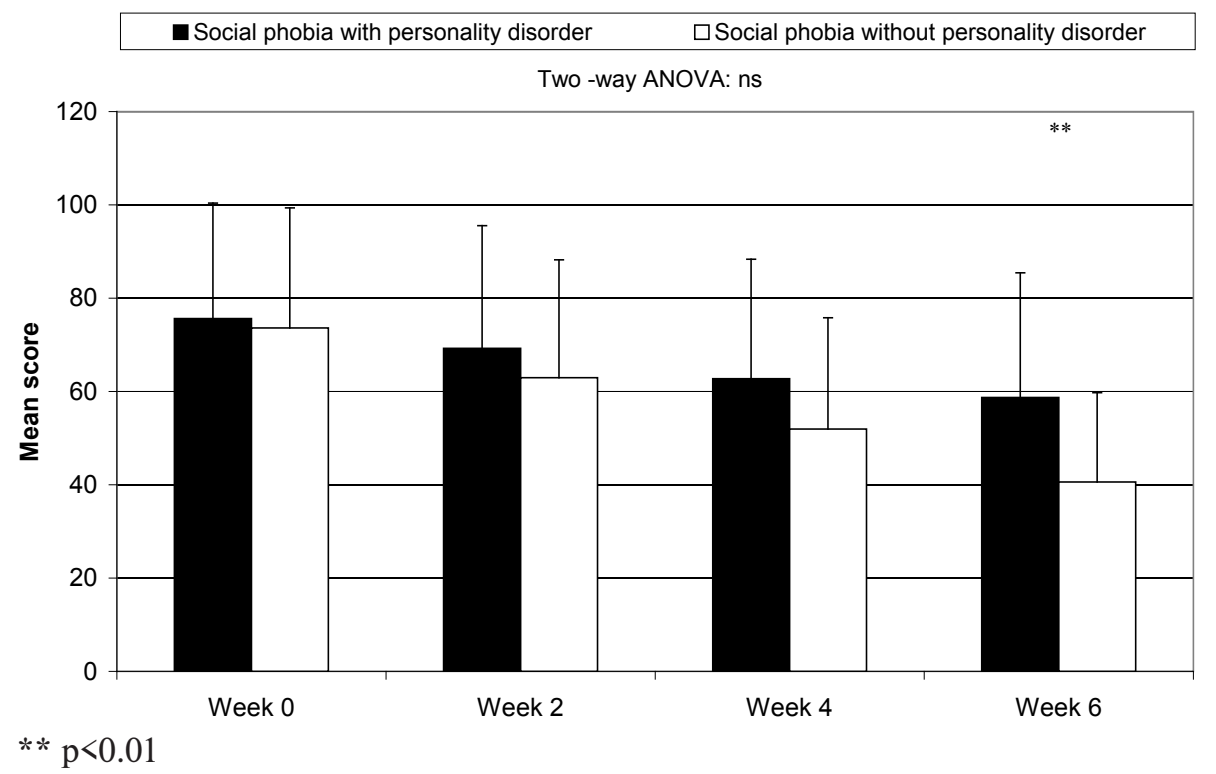

Fig. 6. Liebowitz Social Anxiety Scale - Total score.

\section{- LSAS}

Liebowitz Social Anxiety Scale (LSAS) is most important for evaluating the effectiveness of therapy. The items measure anxiety and avoidant behavior in different social situations. Total score then arises from the sum of the items of anxiety and avoidant behavior.

Anxiety subscale of LSAS (LSAS-AX): There were no statistically significant differences at the beginning between the groups (mean score $41.12 \pm 10.78$ for patients with personality disorders versus $37.61+12.87$ in patients without personality disorder, unpaired t-test: ns). During the treatment, both groups significantly improved (mean score $32.41 \pm 11.55$, one-way ANOVA for repeated measures: $\mathrm{p}<0.0001$ in patients with personality disorders versus $21.78 \pm 10.28$ in patients without personality disorders, one-way ANOVA for repeated measures: $\mathrm{p}<0.0001$ ). There was no statistically significant interaction between groups and time in the two-way ANOVA for repeated measures $(F=0.757 ; p=0.520)$ (Fig. 4).

Avoidant behavior subscale (LSAS-AB): There was no statistically significant difference between groups at the beginning (mean score $34.53 \pm 14.72$ for patients with personality disorders versus $35.39+13.51$ for patients without personality disorders, unpaired t-test: ns). The mean scores of both groups decreased during treatment (the group with a personality disorder to a mean score $25.65 \pm 15.94$, one-way ANOVA for repeated measures: $\mathrm{p}<0.005$, while the group without personality disorders to the mean score $18.61 \pm 9.80$, one-way ANOVA for repeated measures: $p<0.001$ ). There was no statistically significant interaction between groups and time in twoway ANOVA for repeated measures $(F=0.088 ; p=0.768)$ (Fig. 5). 
Total score (LSAS-T): There was a no statistically significant difference between mean scores for groups at the beginning (mean score $75.65+24.74$ of patients with personality disorders versus $73.61 \pm 25.76$ of patients without personality disorders, unpaired t-test: ns.). Both group improved during treatment (mean score of patients with personality disorder was $58.71+26.72$, one-way ANOVA for repeated measures: $p<0.005$ vs mean score $40.61 \pm$ 19.12 for patients without personality disorders; one-way ANOVA for repeated measures: $\mathrm{p}<0.0001)$. There was no statistically significant interaction between groups and time in the two-way ANOVA for repeated measures $(\mathrm{F}=$ 0.636; $p=0.593$ ) (Fig. 6).

\section{DISCUSSION}

The results show that patients from both groups improved significantly on all ratings scales. A combination of CBT and pharmacotherapy proved to be the most effective treatment for patients suffering from social phobia with or without comorbid personality disorder. Treatment efficacy in patients with social phobia without personality disorder was shown to be slightly better than the group with social phobia comorbid with personality disorder but according the quantitative rating scales (objective and subjective) the differences between groups did not reach statistical significance. Nevertheless more patients without personality disorder reached the clinical remission than patient with personality disorder. Thus it is possible that the intensive 6-week group CBT program is long enough for patients with social phobia without a personality disorder, while it is too short for patients with social phobia with personality disorder. Another hypothesis - that in addition to social phobia, personality disorder patients would more frequently suffer from other comorbid disorders - was confirmed. The presence of comorbid disorders has been associated with longer duration of social phobia as well as a more severe impairment before and after cognitive-behavioral therapy treatment ${ }^{33}$.

There are surprising results for the Beck Anxiety Inventory. The general anxiety symptoms increased in the second week of the treatment for both groups. We believe that this initial rise in anxiety symptoms is a consequence of the start of the exposure therapy. The mean scores of BAI decreased in subsequent weeks in both groups.

The anxiety level of both groups of patients during therapy significantly improved on the Liebowitz Social Anxiety Scale, which is the most important instrument for the measurement of social phobia symptom severity. The outcome was not significantly better in patients without personality disorders than in patients with personality disorders. There was improvement in the avoidant behavior subscale in both groups. The change was also not significantly higher in patients without personality disorders. Surprisingly we did not find any prominent disproportion between the objective and subjective measures of rating scales between group of personality disorder patients and group of patients without personality disorders.
There were statistically significant differences between the groups in depressive symptoms measured with the Beck depression inventory at the start of the treatment. It seems that the patients with social phobia with a personality disorder entered into the study with more depressive symptoms than patients without personality disorders. This fact can affect the whole course of treatment, because a higher level of subjective depressive symptoms is associated with worse collaboration with exposure therapy. However, there was only mild severity of depression among the patients with social phobia and personality disorders on average. There are several another limitations of our study. Although no significant differences between treatment groups were detected, the patients without personality disorders had a somewhat greater reduction in LSAS and CGI. Our negative findings may be related to type II error. There is also a small group size. Therefore the comparisons of these two groups have limitations.

Perry and Bond ${ }^{23}$ claim that, despite earlier assumptions about untreatability; treatment of personality disorders is relatively effective. In all studies they reviewed, the improvement in personality disorder patients was not as pronounced as in patients without personality disorders but it exists. Our group described similar results in an earlier study with panic disorder and personality disorders ${ }^{24}$.

\section{CONCLUSION}

Patients suffering from social phobia and comorbid personality disorder showed a decrease in specific social phobia symptomatology during the intensive short 6 week treatment even though the results were less pronounced than those for patients suffering from social phobia without personality disorder.

\section{AKNOWLEDGEMENT}

This paper was supported by the research grant IGA MZ ČR NS 9752- 3/2008.

\section{REFERENCES}

1. Kessler RC, McGonagle K, Zhao S, Nelson C, Hughes M, Eschleeman S, Wittchen HU and Kendler KS. Lifetime and 12-months prevalence of DSM-III-R psychiatric disorders in the United States. Arch Gen Psychiatry 1994;51:8-19.

2. Liebowitz MR, Gorman JM, Fyer AJ, Campeas R, Levin AP, Sandberg D, Hollander E, Papp L, Goetz D. Pharmacotherapy of social phobia: an interim report of a placebo-controlled comparison of phenelzine and atenolol. J Clin Psychiatry 1988;49:252-257.

3. Prasko J. Anxiety disorders [Úzkostné poruchy, Czech language]. Prague: Portal 2005.

4. Regier DA, Farmer ME, Rae DS, Locke BZ, Keith SJ, Judd LL, Goodwin FK. Comorbidity of mental disorders with alcohol and other drug abuse: results from the Epidemiologic Catchment Area (ECA) study. JAMA 1990;264: 2511-2518.

5. Agras WS. Treatment of social phobias. J Clin Psychiatry 1990;51 (suppl.):52-58. 
6. Davidson JRT, Hughes DC, George LK, Blazer DG. The epidemiology of social phobia: findings from the Duke Epidemiological Catchment Area Study. Psychol Med 1993;23:709-718.

7. Davidson JRT, Versiani M. International Advances in the treatment of social phobia. J Clin Psychiatry 1994;55:3. (Academic Highlights)

8. Delong $\mathrm{H}$ and Pollack MH. Update on the Mark H. Pollack, M.D.Assessment, diagnosis, and treatment of individuals with social anxiety disorder. Focus 2008;6:431-437.

9. Heimberg RG, Jester HR. Cognitive behavioral treatments: literature review, in Social Phobia: Diagnosis, Assessment and Treatment. Edited by Heimberg RG, Liebowitz MR, Hope DA, Schneier FR. New York, Guilford Press, 1995.

10. Heimberg RG. Cognitive-behavioral therapy for social anxiety disorder: current status and future directions. Biol Psychiatry 2002; 51:101-108.

11. Gould RA, Pollack MH, Yap L. Cognitive-behavioral and pharmacological treatment for social phobia: a meta-analysis. Clin Psycho Sci Pract 1997;4:291-306.

12. Otto MW, Pollack MH, Gould RA, Worthington JJ 3rd, McArdle ET, Rosenbaum JF. A comparison of the efficacy of clonazepam and cognitive-behavioral group therapy for the treatment of social phobia. J Anxiety Disord 2000;14:345-358.

13. Heimberg RG, Liebowitz MR, Hope DA, Schneier FR, Holt CS, Welkowitz LA, Juster HR, Campeas R, Bruch MA, Cloitre M, Fallon B, Klein DF. Cognitive behavioral group therapy vs phenelzine therapy for social phobia: 12-week outcome. Arch Gen Psychiatry 1998;55:1133-1141.

14. Liebowitz MR, Heimberg RG, Schneier FR, Hope DA, Davies S, Holt CS, Goetz D, Juster HR, Lin SH, Bruch MA, Marshall RD, Klein DF. Cognitive behavioral group therapy versus phenelzine in social phobia: long-term outcome. Depress Anxiety 1999;10:89-98.

15. Heimberg RG. Specific issues in the cognitive-behavioral treatment of social phobia. J Clin Psychiatry 1993;54(suppl):36-45.

16. Taylor S. Meta-analysis of cognitive-behavioral treatments for social phobia. J Behav Ther Exp Psychiatry 1996;27:1-9.

17. Prasko J, Dockery C, Horacek J, Houbova P, Kosova J, Klaschka J, Paskova B, Praskova H, Seifertova D, Zalesky R, Hoschl C. Moclobemide and cognitive behavioral therapy in the treatment of social phobia. A six-month controlled study and 24 months follow up. Neuro Endocrinol Lett 2006;27:473-481.

18. Foa EB, Franklin ME, Moser J. Context in the clinic: how well do cognitive-behavioral therapies and medications work in combination? Biol Psychiatry 2002;52:987-997.
19. Lenzenweger MF, Loranger AW, Korfine L, Neff C. Detecting personality disorders in a nonclinical population. Arch Gen Psychiatry 1997;54:345-351.

20. Koenigsberg HW, Kaplan RD, Gilmore MM, Cooper AM. The relationship between syndrome and personality disorder in DSM-III: experience with 2,462 patients. Am J Psychiatry 1985;142:207-212.

21. Loranger AW. The impact of DSM-III on diagnostic practice in a university hospital. Arch Gen Psychiatry 1990:47:672-675.

22. Tyrer P \& Davidson K. Management of personality disorder. In: Gelder MG, Lopez-Ibor JJ \& Andreasen A (eds.):New Oxford Textbook of Psychiatry. Oxford University Press 2000;970-978.

23. Perry JC \& Bond M. Empirical studies of psychotherapy for personality disorders. In: Gunderson JG \& Gabbard GO (eds) Psychotherapy for Personality Disorders, Review of Psychiatry Series 19/3, American Psychiatric Press, Washington DC; 2000: $1-32$.

24. Prasko J, Houbova P, Novak T, Zalesky R, Espa-Cervena K, Paskova B, Vyskocilova J. Influence of personality disorder on the treatment of panic disorder. Comparison study. Neuro Endocrinol Lett 2005;26:667-674.

25. Prasko J (eds): Personality disorders [Poruchy osobnosti, Czech language]. Prague: Portal 2003.

26. International Classification of Diseases. $10^{\text {th }}$ revision. Mental and Behavioural Disorders: Diagnostic Criteria for Research (World Health Organization 1990), Prague, Psychiatric Centre 1996.

27. Lecrubier Y, Sheehan DV, Weiller E, Amorin P, Bonora I, Sheehan Harnett K, Janavs J, Dunbar GC. The MINI-international neuropsychiatric interview (M.I.N.I.): a short diagnostic structured interview: reliability and validity according to the CIDI. Eur Psychiatry 1997; 12:224-231.

28. Guy W (ed.): ECDEU Assessment manual for psychopharmacology. Rockville, US DHEW 1976.

29. Liebowitz MR. Social phobia. Mod Problem Pharmacopsychiatry 1987;22:141-173.

30. Beck AT \& Emery G. Anxiety disorders and phobias: A cognitive perspective. New York, Basic Books: 1985.

31. Beck AT, Ward CH, Mendelson M, Mock J, Erbaugh J. An inventory for measuring depression. Arch Gen Psychiatry 1961;4:561-571.

32. Prasko J, Kosova J, Paskova B, Seifertova D. Social phobia and its treatment [Socialni fobie a jeji lecba, Czech language]. Prague: Psychiatric centre 1998.

33. Erwin BA, Heimberg RG, Juster H, Mindlin M. Comorbid anxiety and mood disorders among persons with social anxiety disorder. Behav Res Ther 2002:40:19-35. 